\title{
PENGARUH PRAKTIK KERJA INDUSTRI TERHADAP KESIAPAN KERJA SISWA KELAS XII SMK KARTINI SINTANG
}

\author{
Oleh : Lidya Dau, Munawar Thoharudin, Dessy Triana Relita \\ Sekolah Tinggi Keguruan Dan Ilmu Pendidikan Persada Khatulistiwa Sintang \\ e-mail :DauLidya@gmail.com, Munawar.thoha99@gmail.com., Dssytrianarelita@gmail.com,
}

\begin{abstract}
Abstrak
Penelitian ini bertujuan untuk mengetahui pengaruh praktik kerja industri terhadap kesiapan kerja siswa kelas XII SMK Kartini Sintang Tahun Pelajaran 2017/2018. Metode yang digunakan adalah kuantitatif dan bentuk penelitian yang digunakan adalah eksplanasi survei. Berdasarkan hasil penelitian terhadap 40 responden yang diteliti, diperoleh nilai praktik kerja industri diperoleh rata-rata hitung (Mean) 86,88, median (Me) 86,50, modus (Mode) 85 dan Standart Deviasi 4,127, praktik kerja industri termasuk kategori sangat baik. Berdasarkan Angket variabel kesiapan kerja, diperoleh hasil rata-rata hitung (Mean) 186, median (Me) 188, modus (Mode) 188 dan Standart Deviasi 6,8, kesiapan kerja termasuk kategori Baik. Hasil uji t, diperoleh thitung yaitu sebesar 3,242 dan nilai $\mathrm{t}_{\text {tabel }} \mathrm{dk}=\mathrm{n}-2=38$ dengan nilai signifikan sebesar 0,05 alpha maka $t_{\text {tabel }} 2,024$, diketahui 3,242> $t_{\text {tabel }}$ 2,024, maka hipotesis nol ditolak. Berdasarkan hasil penelitian, dapat disimpulkan bahwa terdapat pengaruh yang signifikan antara praktik kerja industri terhadap kesiapan kerja siswa kelas XII SMK Kartini Sintang Tahun Pelajaran 2017/2018 .
\end{abstract}

Kata Kunci : Praktik Kerja Industri, Kesiapan Kerja.

\section{Abstrack}

This study aimed at determining the effect of industrial work practices on the readiness of students working class XII SMK Kartini Sintang in the academic years of 2017/2018. Based on the results of research on 40 respondents studied, obtained the Mean value of industrial work practice was 86.88 , the median was 86.50 , the mode was 85 and the Deviation Standard was 4.127 , thus industrial work practices belonged to very good category. Based on questionnaires of work preparedness variable, the results obtained the Mean 186, median 188, mode 188 and Deviation Standard 6.8, thus readiness work included Good category. Based on $t_{\text {test }}$ results, obtained $\mathrm{t}_{\text {count }}$ as 3.242 and $\mathrm{t}_{\text {table }}$ value $\mathrm{dk}=\mathrm{n}-2=38$ with a significant value of 0.05 alpha then $\mathrm{t}_{\text {table }} 2.024$, known as 3.242> $\mathrm{t}_{\text {table }} 2.024$, then the null hypothesis rejected. Based on the research results, it could be concluded that there is a significant influence between industrial work practices on the readiness of students working class XII SMK Kartini Sintang in the academic years of 2017/2018

Keywords: Industrial Work Practices, Work Readiness 


\section{PENDAHULUAN}

Era persaingan global yang dihadapi saat ini menuntut akan sumber daya manusia yang berkualitas untuk siap menjadi tenaga kerja professional di bidangnya. Dalam era globalisasi adanya fenomena kerjasama ekonomi internasional yang merupakan suatu bentuk dimana beberapa negara maupun lembaga internasional tergabung didalamnya.

Indonesia sebagai salah satu negara anggota ASEAN saat ini sedang mempersiapkan kerjasama ekonomi internasional, yaitu Masyarakat Ekonomi ASEAN (MEA). Menjelang tahun 2020 perekonomian Indonesia akan berubah dan berkembang kearah perekonomian global, sehingga perusahaan dan industrinya dituntut untuk mampu bersaing dipasar regional maupun global. Era persaingan global yang dihadapi menuntut akan sumber daya manusia yang berkualitas untuk siap menjadi tenaga kerja professional di bidangnya.

Sumber daya manusia yang berkualitas akan menunjang keberlangsungan pembangunan perekonomian negara. SDM yang berkompeten bergantung pula dengan kondisi kesiapan calon tenaga kerja salah satu aspek yang menunjang mencakup aspek keterampilan, pengetahuan dan pengertian lain yang telah dipelajari. Dapat diartikan bahwa pengalaman-pengalaman keterampilan dan pengetahuan yang mempunyai pengaruh positif terhadap kesiapan kerja terutama tentang dunia kerja. Pengembangan SDM dapat dilakukan dengan pendekatan pendidikan formal dan pelatihan. Salah satu program yang dirancang oleh Pemerintah Negara Kesatuan Republik Indonesia adalah dalam bentuk pendidikan formal yaitu Sekolah Menengah Kejuruan (SMK).
Didukung dengan pendapat Miller dalam Hall (2010:21) "The underlying theory that links to work readiness lies in contextual learning. The integration of academic and vocational curriculum helps address the skills required of the 21st century student". Teori yang mendasari hubungan dengan kesiapan kerja terletak pada pembelajaran kontekstual. Integrasi akademik dan kurikulum kejuruan membantu memperbaiki keterampilan yang dibutuhkan siswa abad ke-21.

Menurut Undang-undang Republik Indonesia Nomor 20 Tahun 2003 tentang Sistem Pendidikan Nasional Bab VI pasal 15 pengertian dari Sekolah Menengah Kejuruan merupakan "pendidikan menengah yang mempersiapkan peserta didik terutama untuk bekerja di bidang tertentu". Sekolah Menengah Kejuruan memiliki pola pelatihan khusus yaitu dengan praktik kerja industri untuk mempersiapkan peserta didik sebagai SDM yang profesional dan siap kerja. SMK Kartini Sintang adalah salah satu lembaga pendidikan formal yang ada di kota Sintang, yang bertanggung jawab dan turut serta dalam menghasilkan tenaga kerja yang terampil. Dalam program praktik kerja industri pada SMK Kartini Sintang beberapa indikator atau kriteria yang telah ditetapkan yaitu : disiplin waktu/disiplin kerja, kemauan/motivasi kerja, inisiatif kerja \& kreatifitas, kualitas kerja, sikap dan perilaku. Melalui kegiatan Praktik Kerja Industri tersebut, siswa diharapkan memiliki kesiapan kerja sehingga setelah kelulusan dengan harapan siswa dapat meningkatkan kualitas dan keterampilan serta menjadi tenaga kerja sesuai dengan bidang keahlian mereka masing-masing yang berdaya saing tinggi dalam persaingan global. 
Berdasarkan dengan uraian diatas dengan program Praktik Industri akan mempersiapkan kesiapan siswa untuk memasuki dunia kerja hal ini mendorong peneliti untuk mengadakan penelitian dengan judul "Pengaruh Praktik Kerja Industri Terhadap Kesiapan Kerja Siswa Kelas XII SMK Kartini Sintang”. Adapun tujuan dari penelitian ini adalah untuk mengetahui pengaruh praktik kerja industri terhadap kesiapan kerja siswa kelas XII SMK Kartini Sintang Tahun Pelajaran 2017/2018.

\section{METODE PENELITIAN}

Pendekatan yang digunakan dalam penelitian ini menggunakan pendekatan kuantitatif, pendekatan kuantitatif digunakan karena penelitian lebih fokus pada data-data numerik (angka) yang dianalisis menggunakan teknik statistik. Bentuk penelitian yang digunakan adalah format eksplanasi survei. Menurut Bungin, 2013: 46 format eksplanasi survei adalah "Format eksplanasi survei dimaksud untuk menjelaskan suatu generalisasi sampel terhadap populasinya atau menjelaskan hubungan, perbedaan, atau pengaruh satu variabel dengan variabel yang lain. karena itu penelitian eksplanasi menggunakan sampel dan hipotesis. Untuk menguji hipotesis digunakan statistik inferensial".

Format eksplanasi survei digunakan untuk memperoleh gambaran apakah terdapat pengaruh antara variabel praktik kerja industri (X) dan variabel kesiapan kerja (Y) siswa kelas XII SMK Kartini Sintang Tahun Pelajaran 2017/2018. Populasi pada penelitian ini adalah seluruh siswa kelas XII SMK Katini Sintang Tahun Pelajaran 2017/2018, yang berjumlah 40 orang.
Dalam penelitian ini tidak menggunakan sampel, melainkan seluruh populasi yang diteliti. Didukung oleh pendapat menurut Arikunto (2014: 174) bahwa: "Penelitian populasi dilakukan apabila peneliti ingin melihat semua liku-liku atau keadaan yang ada didalam populasi tersebut, dan jumlah populasinya juga tidak terlalu banyak".

\section{HASIL DAN PEMBAHASAN Hasil Penelitian}

Hasil penelitian: Berdasarkan dengan nilai praktik kerja industri dengan jumlah siswa 40, diperoleh gambaran variabel praktik kerja industri (X) yaitu rata-rata hitung (Mean) 86,88, median (Me) 86,50, modus (Mode) 85 dan Standart Deviasi 4,127. Penyebaran data terbesar pada kelas interval $86-88,6$ yaitu sebesar $30 \%$, yang berada pada rentang di bawahnya pada kelas interval 8082,6 sebanyak $20 \%$ dan sebanyak $7,5 \%$ di atas rentang rata-rata. Secara keseluruhan termasuk kategori sangat baik. Berdasarkan jumlah responden angket berjumlah 40 siswa, diperoleh gambaran variabel kesiapan kerja (Y) yaitu rata-rata hitung (Mean) 186, median (Me) 188, modus (Mode) 188 dan Standart Deviasi 6,8. Penyebaran data terbesar pada kelas interval 187-193 yaitu sebesar 37,5\% dan yang berada pada rentang di bawahnya terdapat di kelas interval 166-173 sebanyak $5 \%$ dan sebanyak $20 \%$ di atas rentang ratarata. Secara keseluruhan dapat dikatakan bahwa sebagian besar kesiapan kerja termasuk kategori Baik. 
Tabel 1:Uji normalitas

\begin{tabular}{lll}
\hline & \multicolumn{2}{l}{ One-Sample Kolmogorov-Smirnov Test } \\
\hline $\mathrm{N}$ & & Unstandardized Residual \\
\hline Normal Parameters & & 40 \\
\hline Most Extreme Differences & Mean &, 0000000 \\
\cline { 2 - 3 } & Std. Deviation & 3,14020650 \\
\cline { 2 - 3 } & Absolute &, 147 \\
\cline { 2 - 3 } & Positive &, 069 \\
\cline { 2 - 3 } Tegative &,- 147 \\
\hline Asymp. Sig. (2-tailed) & &, 147 \\
\hline
\end{tabular}

a. Test distribution is Normal.

b. Calculated from data.

Berdasarkan hasil perhitungan uji normalitas berbantuan program komputer SPSS versi 18 pada Tabel 1, nilai signifikan sebesar 0,259>0,05, Karena nilai signifikan lebih besar dari 0,05, maka dapat disimpulkan bahwa data berdistribusi normal.

Tabel 2: Uji Linieritas

\begin{tabular}{|c|c|c|c|c|c|c|c|}
\hline \multicolumn{8}{|c|}{ ANOVA Table } \\
\hline 7 & & & $\begin{array}{l}\text { Sum of } \\
\text { Squares }\end{array}$ & df & $\begin{array}{l}\text { Mean } \\
\text { Square }\end{array}$ & $\mathrm{F}$ & Sig. \\
\hline Kesiapan & Between & (Combined) & 164,044 & 11 & 14,913 & 1,277 & ,287 \\
\hline Kerja * & Groups & Linearity & 106,400 & 1 & 106,400 & 9,113 &, 005 \\
\hline Praktik & & Deviation from Linearity & 57,644 & 10 & 5,764 & ,494 &, 880 \\
\hline Kerja & Within $\mathrm{G}$ & oups & 326,931 & 28 & 11,676 & & \\
\hline Industri & Total & & 490,975 & 39 & & & \\
\hline
\end{tabular}

Berdasarkan hasil perhitungan berbantuan program komputer SPSS versi 18 pada Tabel 1, diperoleh nilai signifikan $\mathrm{X}$ terhadap $\mathrm{Y}=0,880$. Angka $0,880>0,05$. Nilai tersebut mengindikasikan bahwa model regresi dalam penelitian ini adalah linear, karena hasil uji linear tersebut adalah linear, maka analisis yang digunakan adalah regresi linear.
Analisis Regresi Sederhana

Berdasarkan hasil output SPSS pada Tabel 3, diketahui nilai konstant untuk kolom Unstandardized Cofficients B untuk kesiapan kerja sebesar $\mathrm{a}=58,209$. Praktik kerja industri sebesar $b=0,400$. Jadi dapat diketahui jika persamaan regresi tersebut adalah $\mathrm{Y}=$ $58,209+0,400 \mathrm{X}$ 
Tabel 3: Uji Analisis Regresi Sederhana

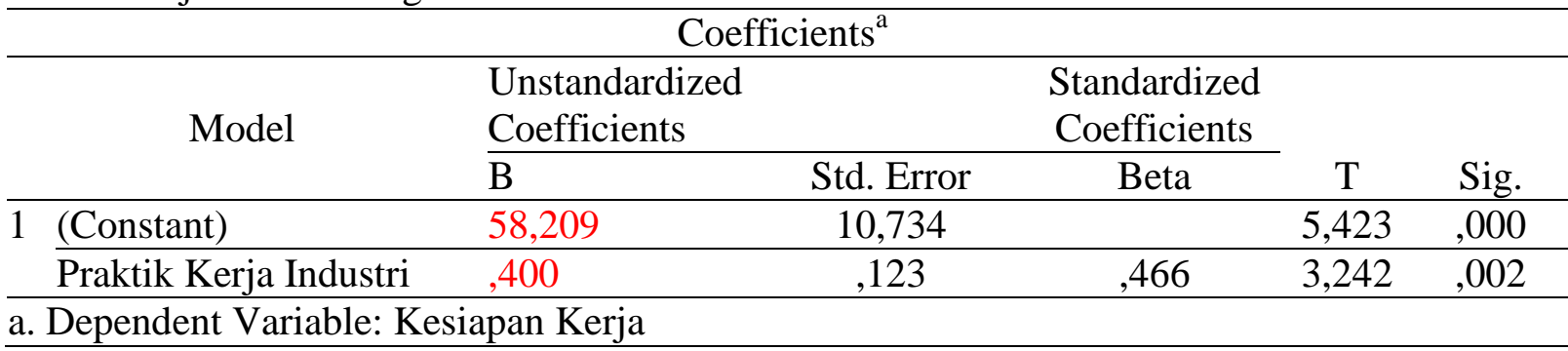

Dari persamaan regresi tersebut dapat diartikan bila praktik kerja industri bertambah sebesar satu satuan menyebabkan peningkatan kesiapan kerja sebesar 0,400. Maka persamaan regresi tersebut menunjukan adanya pengaruh positif dari Praktik kerja industri. Setiap peningkatan kekuatan nilai pada Praktik kerja industri akan meningkatkan kesiapan kerja siswa.

Tabel 4: Uji r /Correlations

\begin{tabular}{llcc}
\hline & & $\begin{array}{c}\text { Kesiapan } \\
\text { Kerja }\end{array}$ & Praktik Kerja Industri \\
\hline Kesiapan Kerja & PearsonCorrelation & 1 &, 466 \\
\cline { 2 - 4 } & Sig. (2-tailed) & 40 &, 002 \\
\cline { 2 - 4 } & $\mathrm{N}$ &, $466^{* *}$ & 40 \\
\hline $\begin{array}{l}\text { Praktik kerja } \\
\text { Industri }\end{array}$ & PearsonCorrelation &, 002 & 1 \\
\cline { 2 - 4 } & Sig. (2-tailed) & 40 & 40 \\
\cline { 2 - 4 } & $\mathrm{N}$ & & \\
\hline
\end{tabular}

**. Correlation is significant at the 0.01 level (2-tailed).

Berdasarkan hasil output SPSS pada Tabel 4, nilai $r$ sebesar 0,466 dan angka tersebut nilai "r pearson correlations" sebesar 0,466 bernilai positif. Hal ini menandakan bahwa dan Sig. (2-tailed) sebesar 0,002<0,05 maka jika terjadi peningkatan nilai pada variabel $\mathrm{H}_{0}$ ditolak. Dari tabel hasil perhitungan uji $\mathrm{r}$ bebas maka nilai pada variabel terikat juga (korelasi) tersebut dapat kita ketahui bahwa akan ikut meningkat

Tabel 5: Uji R Square (Uji Pengaruh)

\begin{tabular}{ccccc}
\hline \multicolumn{5}{c}{ Model Summary $^{\mathbf{b}}$} \\
\hline Model & R & R Square & Adjusted R Square & Std. Error of the Estimate \\
\hline 1 &, $466^{\mathrm{a}}$ &, 217 &, 196 & 3,181 \\
\hline
\end{tabular}

Berdasarkan nilai output pada Tabel 5 dapat diketahui bahwa kontribusi atau keefektifan dari variabel independen praktik kerja industri terhadap variabel dependen kesiapan kerja siswa adalah sebesar 21,7\%.dan $78,3 \%$ dipengaruhi oleh faktor lain yang tidak diteliti dalam penelitian ini 
Tabel 6: Uji $t /$ Coefficients $^{\mathrm{a}}$

\begin{tabular}{|c|c|c|c|c|c|c|}
\hline \multirow{2}{*}{\multicolumn{2}{|c|}{ Model }} & \multicolumn{2}{|c|}{$\begin{array}{c}\text { Unstandardized } \\
\text { Coefficients }\end{array}$} & \multicolumn{2}{|c|}{$\begin{array}{l}\text { Standardized } \\
\text { Coefficients }\end{array}$} & \multirow[b]{2}{*}{ Sig. } \\
\hline & & $\mathrm{B}$ & Std. Error & Beta & $\mathrm{T}$ & \\
\hline \multirow[t]{2}{*}{1} & (Constant) & 58,209 & 10,734 & & 5,423 &, 000 \\
\hline & Praktik Kerja Industri & 400 &, 123 & ,466 & 3,242 &, 002 \\
\hline
\end{tabular}

Berdasarkan output SPSS pada Tabel 6, nilai $t_{\text {hitung }}$ sebesar 3,242. Diketahui nilai $t_{\text {tabel }}$ $\mathrm{dk}=\mathrm{n}-2$, maka diperoleh $\mathrm{t}_{\text {tabel }}$ sebesar 2,024. Dari hasil perhitungan tersebut dapat diketahui nilai dari $t_{\text {hitung }}>t_{\text {tabel. }}$. Dari hasil perhitungan tersebut, dapat diketahui bahwa terdapat pengaruh positif dari variabel Praktik kerja industri secara parsial terhadap kesiapan kerja siswa tetapi $t_{\text {hitung }} 3,242>t_{\text {tabel }}$ sebesar 2,024 berarti penelitian ini menerima hipotesis alternatif $\left(\mathrm{H}_{\mathrm{a}}\right)$ dan menolak hipotesis nol $\left(\mathrm{H}_{0}\right)$.

\section{Pembahasan Hasil Penelitian}

Menurut keputusan Menteri

Pendidikan dan kebudayaan RI Nomor 323/U/1997 bahwa prakerin adalah suatu program yang bersifat wajib yang merupakan bagian dari program Pendidikan Sistem Ganda (PSG) dalam pedoman praktis pelaksanaan pendidikan sistem ganda (PSG) pada SMK disebutkan bahwa prakerin adalah praktik keahlian produktif yang dilaksanakan di industri atau perusahaan yang berbentuk kegiatan mengerjakan kegiatan produksi atau jasa.Menurut Firdaus dalam Nurjanah ( 2015 : 19 ) menyatakan bahwa, "Praktik Kerja Industri (Prakerin) merupakan bagian dari pendidikan sistem ganda yang merupakan inovasi pendidikan SMK yang mana peserta didik melakukan magang (Appreticeship) di industri yang relevan dengan kompetensi keahliannya selama kurun waktu tertentu".

Berdasarkan nilai praktik kerja industri dengan jumlah siswa 40, diperoleh gambaran variabel praktik kerja industri $(\mathrm{X})$ yaitu rata-rata hitung (Mean) 86,88, median (Me) 86,50, modus (Mode) 85 dan Standart Deviasi 4,127. Secara keseluruhan termasuk kategori sangat baik karena hasil dari praktik kerja industri Kriteria di SMK Kartini Sintang diatas Ketuntasan Minimal yang ditetapkan sebesar 75. Dapat disimpulkan bahwa hasil nilai dari praktik kerja industri siswa kelas XII di SMK Kartini Sintang Tahun Pelajaran $2017 / 2018$

Menurut Firdaus dalam Nurjanah (2015: 11) kesiapan Kerja adalah suatu proses untuk mencapai suatu tujuan yang melibatkan pengembangan kerja peserta didik yang meliputi sikap, nilai, pengetahuan dan keterampilan. Sedangkan menurut Drever ( dalam Slameto 2013 : 59), Kesiapan atau Readiness adalah kesediaan memberi respon atau bereaksi. Menurut Slameto (2015:113), "kesiapan adalah keseluruhan kondisi seseorang yang membuatnya siap untuk memberi respon atau jawaban di dalam cara tertentu terhadap suatu situasi".

Berdasarkan hasil penelitian mengenai kesiapan kerja siswa di kelas XII di SMK Kartini Sintang Tahu Pelajaran 2017/2018, diperoleh gambaran variabel kesiapan kerja 
(Y) yaitu rata-rata hitung (Mean) 186, median (Me) 188, modus (Mode) 188 dan Standart Deviasi (SD) 6,8. Secara keseluruhan dapat dikatakan bahwa sebagian besar kesiapan kerja termasuk kategori Baik. Dapat disimpulkan bahwa hasil dari kesiapan kerja siswa kelas XII di SMK Kartini Sintang Tahun Pelajaran 2017/2018 secara keseluruhan termasuk kategori sangat baik.

Pengaruh Praktik Kerja Industri Terhadap Kesiapan Kerja Siswa Kelas XII SMK Kartini Sintang Tahun Pelajaran 2017/2018. Berdasarkan hasil penelitian yang diperoleh maka peneliti dapat menganalisa pengaruh Praktik Kerja Industri Terhadap Kesiapan Kerja Siswa Kelas XII SMK Kartini Sintang Tahun Pelajaran 2017/2018 dengan terlebih dahulu menghitung validitas instrumen dan reliabilitas. Setelah itu dilanjutkan dengan menghitung tingkat keeratan pengaruh antara 2 variabel dengan korelasi product moment.

Berdasarkan hasil perhitungan diketahui antara praktik kerja industri terhadap kesiapan kerja nilai uji $\mathrm{r}$ (korelasi) pada "r pearson correlationsl" sebesar $0,466 * *$ (**. Correlation is significant at the 0.01 level 2-tailed) angka tersebut bernilai positif dan nilai signifikan (2-tailed) sebesar $0,002<0,05$ maka $\mathrm{H}_{0}$ ditolak artinya terdapat hubungan yang signifikan antara praktik kerja industri terhadap kesiapan kerja. Berdasarkan hasil perhitungan di atas diperoleh $\mathrm{R}^{2} 21,7 \%$ perubahan pada kesiapan kerja sedangkan $78,3 \%$ dipengaruhi oleh faktor lain yang tidak diteliti dalam penelitian ini.

Berdasarkan hasil perhitungan diperoleh $t_{\text {hitung }}$ praktik kerja industri 3,242 dengan nilai signifikan sebesar 0,002 (lebih kecil dari taraf kesalahan 0,05). Dimana taraf
0,05 dan derajat kebebasab $\mathrm{dk}=40-2, \mathrm{dk}=38$ untuk $t_{\text {tabel }}$ 2,024. Diketahui bahwa $t_{\text {hitung }}$ $3,242>t_{\text {tabel }}$ 2,024. berarti penelitian ini menerima hipotesis alternatif $\left(\mathrm{H}_{\mathrm{a}}\right)$ dan menolak hipotesis nol $\left(\mathrm{H}_{0}\right)$ bahwa terdapat hubungan yang signifikan antara praktik kerja industri terhadap kesiapan kerja.

Hasil penelitian ini diperkuat dengan penelitian-penelitian yang telah dilakukan oleh Majid N.W.A (2013) menyimpulkan bahwa Pengaruh Pengalaman Praktik Kerja Industri Dan Kompetensi Teknologi Informasi Komunikasi maka akan memberikan dampak yang positif pula Terhadap Kesiapan Kerja Kelas XII SMK Negeri 3 Yogyakarta. Diketahui bahwa signifikansi t untuk pengalaman praktik kerja industri(X1) sebesar 0,000 pada tingkat signifikansi 0,05 . Besarnya $\mathrm{t}_{\text {tabel }}(\alpha=0,05)$ (dari rumus df $=\mathrm{n}-\mathrm{k}=30-2$ ) 2,0484. Karena signifikansi variabel pengalaman praktik kerja industri0,000 lebih kecil dari signifikansi alpha $(\alpha)$ 0,05 dan $t_{\text {hitung }} 4,019$ lebih besar dari pada $t_{\text {tabel }}(2,0484)$, maka hipotesis nol (H0) ditolak dan hipotesis alternatif (Ha) diterima. Hal ini berarti dapat dibuktikan bahwa variabel independen (pengalaman praktik kerja industri) berpengaruh positif dan signifikan terhadap variabel dependen (kesiapan kerja).

Huda F.A. (2015) Pengaruh Praktik Kerja Industri, Kompetensi Kejuruan, Dan Kondisi Sosial Ekonomi Orang Tua memiliki pengaruh yang positif dan signifikan Terhadap Minat Kerja dan Kesiapan Kerja Siswa SMK Keahlian Teknik Komputer dan Jaringan di Kota Sintang. Dimana Praktik kerja industri memiliki pengaruh terhadap kesiapan kerja ditujukkan pada nilai sig. $=0,009$ sehingga lebih kecil dari nilai 
probabilitas 0,05 atau 0,05>0,009.Nurjanah I.T.W (2015) mengemukakan bahwa Praktik Kerja Industri Memiliki Pengaruh Yang Positif dan Signifikan Terhadap Kesiapan Kerja Kerja Siswa Kelas XII Kompetensi Keahlian Administrasi Perkantoran SMK Negeri 1 Wonosari. Pengaruh signifikansi hipotesis penelitian diketahui dengan uji t. Apabila thitung lebih besar dari tabel maka variabel bebas memiliki pengaruh yang signifikan terhadap variabel terikat. Berdasarkan hasil uji t diperoleh $\mathrm{t}_{\text {hitung }} 6,354$; sementara $t_{\text {tabel }}$ dengan $\mathrm{dk}=(\mathrm{n}-2=84)$ pada taraf signifikansi 5\% adalah 2,000. Dengan demikian ${ }^{\mathrm{t}}$ hitung lebih besar dari ${ }^{\mathrm{t}}$ tabel $(6,354$ $>2,000)$ sehingga praktik kerja industri (X) berpengaruh signifikan terhadap kesiapan kerja siswa (Y).

Berdasarkan uraian hasil analisis regresi sederhana tersebut, maka dapat disimpulkan bahwa "terdapat pengaruh yang positif dan signifikan praktik kerja industri terhadap kesiapan kerja siswa kelas XII Kompetensi Keahlian Administrasi Perkantoran SMK Negeri 1 Wonosari". Dengan demikian, hipotesis penelitian yang diajukan dalam penelitian ini diterima.

Rachman A. N (2013) menyimpulkan bahwa Pengaruh Praktik Kerja Industri Dan Pengetahuan K3 memiliki pengaruh yang positif dan signifikan Terhadap Kesiapan Kerja Siswa Kelas XII SMK Piri 1 Yogyakarta.

Diketahui besarnya konstanta $(\mathrm{a})=$ 54,322 dan nilai koefisien regresi $(b)=0,438$. Persamaan garis regresi dapat dinyatakan dalam persamaan $\mathrm{Y}=54,322+0,438 \mathrm{X} 1$. Koefisien korelasi $\mathrm{X}$ terhadap $\mathrm{Y}$ sebesar 0,433, karena koefisien korelasi (rx1,y) tersebut bernilai positif maka dapat diketahui bahwa terdapat hubungan yang positif antara Praktik Kerja Industri terhadap kesiapan kerja siswa kelas XII SMK PIRI 1 Yogyakarta Uji signifikansi menggunakan uji t, berdasarkan hasil uji t diperoleh thitung sebesar 5,797. Jika dibandingkan dengan $t_{\text {tabel }}$ sebesar 1,66 pada taraf signifikansi 5\%, maka thitung lebih besar dari $t_{\text {tabel }}(5,797>1,66)$ atau sig $(0,00$ $<0,05)$ sehingga Praktik Kerja Industri mempunyai pengaruh positif dan signifikan terhadap kesiapan kerjasiswa kelas XII SMK PIRI 1 Yogyakarta.

Sari R. (2012) mengatakan bahwa peran praktik industri berpengaruh positif terhadap dalam menunjang kesiapan memasuki dunia kerja siswa kelas XI program keahlian busana SMK Karya Rini Yogyakarta. berdasarkan perhitungan uji hipotesis menggunakan analisis korelasi product moment yang telah diuraikan sebelumnya diperoleh nilai rxy sebesar 0,425 dan nilai nilai $r_{\text {tabel }}$ sebesar 0,355 dalam taraf signifikansi $5 \%$, sehingga $r x y>r_{\text {tabel }}(0,425>$ 0,355). Hal tersebut menunjukkan bahwa terdapat peran yang efektif antara praktik industri dengan kesiapan kerja dibidang busana pada siswa kelas XII Program Keahlian Tata Busana SMK Karya Rini Yogyakarta.

Berdasarkan pembahasan peneliti dan didukung penelitian yang relevan oleh peneliti yang terdahulu maka dapat disimpulkan bahwa terdapat pengaruh yang positif dan signifikan pada penelitian yang berjudul pengaruh praktik kerja industri terhadap kesiapan kerja siswa kelas XII di SMK Kartini Sintang Tahun Pelajaran 2017/2018. 


\section{SIMPULAN DAN SARAN \\ Simpulan}

Berdasarkan hasil penelitian dan perhitungan tentang pengaruh praktik kerja industri terhadap kesiapan kerja siswa kelas XII SMK Kartini Kartini Tahun Pelajaran 2017/2018 yang telah dilakukan, maka dapat dibuat kesimpulan sesuai dengan prosedur dari penelitian ini sebagai berikut:

Berdasarkan nilai praktik kerja industri dengan jumlah siswa 40, diperoleh gambaran variabel praktik kerja industri (X) yaitu rata-rata hitung (Mean) 86,88, median (Me) 86,50, modus (Mode) 85 dan Standart Deviasi 4,127. Secara keseluruhan termasuk kategori sangat baik karena hasil dari praktik kerja industri Kriteria di SMK Kartini Sintang diatas Ketuntasan Minimal yang ditetapkan sebesar 75 .

Berdasarkan hasil penelitian mengenai kesiapan kerja siswa di kelas XII di SMK Kartini Sintang Tahun Pelajaran 2017/2018, diperoleh gambaran variabel kesiapan kerja (Y) yaitu rata-rata hitung (Mean) 186, median (Me) 188, modus (Mode) 188 dan Standart Deviasi (SD) 6,8.

Berdasarkan hasil perhitungan pengaruh praktik kerja industri secara parsial terhadap kesiapan kerja siswa kelas XII SMK Kartini Kartini Tahun Pelajaran 2017/2018 yang terlihat dari hasil uji $t_{\text {hitung }}$ yaitu $t_{\text {hitung }}$ praktik kerja industri 3,242. Dimana taraf 0,05 dan derajat kebebasab $\mathrm{dk}=40-2, \mathrm{dk}=38$ untuk $t_{\text {tabel }}$ 2,024. Diketahui bahwa $t_{\text {hitung }}$ $3,242>t_{\text {tabel }}$ 2,024. Berarti penelitian ini menerima hipotesis alternatif $\left(\mathrm{H}_{\mathrm{a}}\right)$ dan menolak hipotesis nol $\left(\mathrm{H}_{0}\right)$ bahwa terdapat pengaruh antara praktik kerja industri terhadap kesiapan kerja.

\section{Saran}

Berdasarkan hasil penelitian yang telah dilakukan, maka peneliti dapat sarankan beberapa hal sebagai berikut: Diharapkan kepada sekolah agar terus memotivasi siswa ketika praktik kerja industri sebagai bekal kesiapan kerja. Memberikan informasi mengenai prospek bidang keahlian yang dimiliki siswa, sehingga siswa merasa termotivasi untuk menekuni bidang keahliannya. Memberikan informasi dunia kerja kepada siswa, dengan seminar dan sosialisasi mengenai dunia kerja dengan mendatangkan ahli dari Dinas Tenaga Kerja untuk memberikan gambaran mengenai dunia kerja yang sesungguhnya.

Meningkatkan kualitas dan kuantitas monitoring pratik kerja industri dari pembimbing dengan cara selalu memberikan bimbingan, dorongan dan memantau kemampuan siswa selama praktik kerja industri. Meningkatkan kerjasama terhadap orangtua siswa dan dunia industri agar siswa tekun dan termotivasi dalam melaksanakan praktik kerja industri sebagai bekal kesiapan kerja di masa yang akan datang.

Siswa diharapkan mengikuti praktik kerja industri dengan sungguh-sungguh agar setelah melaksanakan Praktik Kerja Industri maksimal dan siswa lebih siap memasuki dunia kerja. Siswa diharapkan mampu bekerja sama dan berani menerima tanggung jawab serta mampu memanfaatkan waktu secara efektif selama pelaksanan praktik kerja industri dengan dunia industri. 


\section{DAFTAR RUJUKAN}

Arikunto, S. 2014. Prosedur Penelitian Suatu Pendekatan Praktik. Jakarta: PT Rineka Cipta.

Bungin, B. 2013. Metodologi Penelitian Sosial \& Ekonomi Format-format Kuantitatif untuk Studi Sosiologi, Kebijakan Publik, Komunikasi, Manajemen, dan Pemasaran. Jakart a: Kencana Prenada Media Group

Direktorat Pembinaan Sekolah Menengah Kejuruan dikutip pada lama http://psmk.kemdikbud.go.id/konten/, diakses pada Dikmenjur,01/04/ 2017)

Hall Valery. L. 2010. "Work Readiness Of Career And Technical Education High School Students Work Readiness Of Career And Technical Education High School Students " Dissertation Georgia: University Of Georgia (https://getd.libs.uga.edu/pdfs/hall_valery_1_201012_edd.pdf diakses 01 Febuari 2017)

Huda, A. F. 2015. "Pengaruh Praktik Kerja Industri, Kompetensi Kejuruan, Dan Kondisi Sosial Ekonomi Orang Tua Terhadap Minat Kerja Dan Kesiapan Kerja Siswa SMK Keahlian Teknik Teknik Komputer Dan Jaringan Di Kota Sintang Tahun 2015”. Tesis Malang: Universitas Negeri Malang.

Kementerian Pendidikan dan Kebudayaan. 2015. Data Pokok Pendidikan Dasar dan Menengah. (https://dapo.dikdasmen.kemdikbud.go.id/Sekolah, diakses 02 Juli 2017)

Nurjanah, T. I. 2015. "Pengaruh Praktik Kerja Industri Terhadap Kesiapan Kerja Kerja Siswa Kelas XII Kompetensi Keahlian Administrasi Perkantoran SMK Negeri 1 Wonosari”.ePrints@UNY. Issn.25380. (http://eprints.uny.ac.id, diakses 01 Febuari 2017).

Majid, N.W.A 2013. "Pengaruh Pengalaman Praktik Kerja Industri dan Kompetensi TIK Terhadap Kesiapan Kerja Kelas XII SMK 3 Yogyakarta Tahun 2012/2013”. Skripsi Malang: Universitas Negeri Malang. Issn.5682673 (http://eprints.uny.ac.id/ diakses 01 Febuari 2017)

Rachman N. A. 2013. "Pengaruh Praktik Kerja Industri Dan Pengetahuan K3 Terhadap Kesiapan Kerja Siswa Kelas XII SMK Piri 1 Yogyakarta". Artikel Cendikiawan. Skripsi Universitas Negeri Yogyakarta ISSN. 23436 (http://eprints.uny.ac.id, diakses 01 Febuari 2017).

Sari. R. 2012. "Peran Praktik Kerja Inuustrı Dalam Menunjang Kesiapan Memasuki Dunia Kerja Siswa Kelas XI Program Keahlian Busana Smk Karya Rini Yogyakarta". Skripsi Universitas Negeri Yogyakarta ISSN. 6905 (http://eprints.uny.ac.id, diakses 01 Febuari 2017).

Slameto. 2013. Belajar \& Faktor-faktor yang Mempengaruhinya. Jakarta: Rineka

Undang-Undang Republik Indonesia Nomor 20 Tahun 2003 Tentang Sistem PendidikanNasional(https://www.google.co.id/search=undangundangsistempendidi kannasionalpasal15no20tahun2003 diakses 01 Febuari 2017). 